\title{
Typical types - a swan song? Observations on chironomids in the Linnean collec- tions, and corresponding general considerations
}

\author{
Martin Spies \\ Zoologische Staatssammlung München, Münchhausenstr. 21, 81247 München, Germany. \\ E-mail:spies@zi.biologie.uni-muenchen.de
}

\section{Introduction}

At the 18th International Symposium on Chironomidae in Trondheim, Norway, this past July I gave a short presentation to draw attention to an online resource that has become available recently. On webpages provided by the Linnean Society of London, under http://www.linnean-online.org/view/insects/tipula.html, a list of electronic links can be found which use scientific species names made available by Linnaeus in original combination with the genus name Tipula Linnaeus. Each link leads to a series of digital images of pinned adult specimens still preserved in the Linnean collections under the corresponding species name.

On a visit to London in August I then had the opportunity - thanks to the Society's honorary curator of insects and two curators of Diptera at The Natural History Museum - to examine all Linnean specimens known to be extant and to represent species of Chironomidae. Some of the results as presented below are more or less preliminary, as so far the animals could be viewed merely at relatively low magnification, in the dry-pinned and shriveled condition in which they have been preserved all along. State-of-the-science microscopic (and possibly genetic) analysis could be performed only if permission for 'destructive sampling' is applied for, and granted by, the Linnean Society.

\section{Chironomids in the Linnean collections}

The chironomid material comprises five specimens under three species names: 1 male each under Tipula littoralis L., 1758 and T. monilis L., 1758, and 1 male plus 2 females under T. plumosa L., 1758. Only one specimen per species name is accompanied by a hand-written name label (see the online images referred to above; the scale rulers shown are graded in $\mathrm{mm}$ ) but, unless there is evidence to the contrary in a particular case, all specimens are equally eligible for consideration as original type material (Day \& Fitton 1978; the second author now is the responsible curator).

The male under T. littoralis is well-preserved in general, but the posterior end of the abdomen is missing and probably lost. The wing crossvein RM is darkened; the venation pattern and tibial armament are as in 
Chironomini; the fore tarsi are distinctly bearded. The taxonomically relevant evidence is consistent with what Linnaeus treated as the one of his two variant forms of $T$. littoralis that had been collected in forests ("habitat in nemoribus"), e.g. under the variant designators "\#1136" in Linnaeus (1746) and " $\beta$ " in Linnaeus (1760). An alternative possibility of connection to the name Tipula arundineti L., 1760 - raised by a second name label apparently added to the pin relatively recently - can be ruled out, as several observable morphological features differ significantly from Linnaeus' diagnosis for T. arundineti. In any case, without the specimen's hypopygium, current knowledge of external morphology does not allow positive identification. In summary, T. littoralis should remain a nomen dubium in Chironomus Meigen or, more conservatively, in Chironomini.

The male under T. monilis L., judging from what can be evaluated in the pinned condition, looks consistent with the current and long-standing interpretation of the described species as a member of Ablabesmyia Johannsen. However, there is reason to suspect that it might not represent the taxonomic species for which the name A. monilis has been used. For instance, compared to the figures of tibial spurs in Fittkau (1962: 422), especially the midleg spur configuration of the Linnean specimen is like the one ascribed to A. phatta (Egger), not like that labeled "Ablabesmyia monilis" by Fittkau. A slide-mount of the hypopygium would be necessary and likely sufficient to clarify whether this Linnean specimen belongs to any currently recognized species of Ablabesmyia and, if so, to which one.

The third Linnean lot, under T. plumosa L., may raise the most critical questions. As I had suspected from the online images and mentioned at the Trondheim symposium, the three corresponding specimens appear to belong to a species in the currently recognized subgenus Chironomus (Camptochironomus). If so, they would be incompatible with the long-standing application of the name C. plumosus (L.) to a species complex or species in Chironomus (Chironomus). From inspection of the pinned material the Camptochironomus identification is certain so far only for the male in the series, but the two females have not shown any contradicting evidence. Further support comes from the information on the species' larva and sampling sites given by Linnaeus (e.g. 1746: 333 under "\#1135", referred to by Linnaeus 1758: 587 under "plumosa"; see also the next-following reference there). The adult and larval specimens of Tipula plumosa personally examined by Linnaeus (1758) had come from two sites in the Baltic Sea along the coasts of southern Sweden (see also Hirvenoja 2006: 374, and 376 left column). Linnaeus (1746) described the larvae as showing ventral tubules of the posterior abdomen longer than the posterior parapods. This fits the 'plumosus type' known, e.g., from larvae currently placed in Camptochironomus, but not the 'semireductus type' shown by brackish-water specimens subsumed in recent taxonomic concepts to which the name C. plumosus (L.) has been applied.

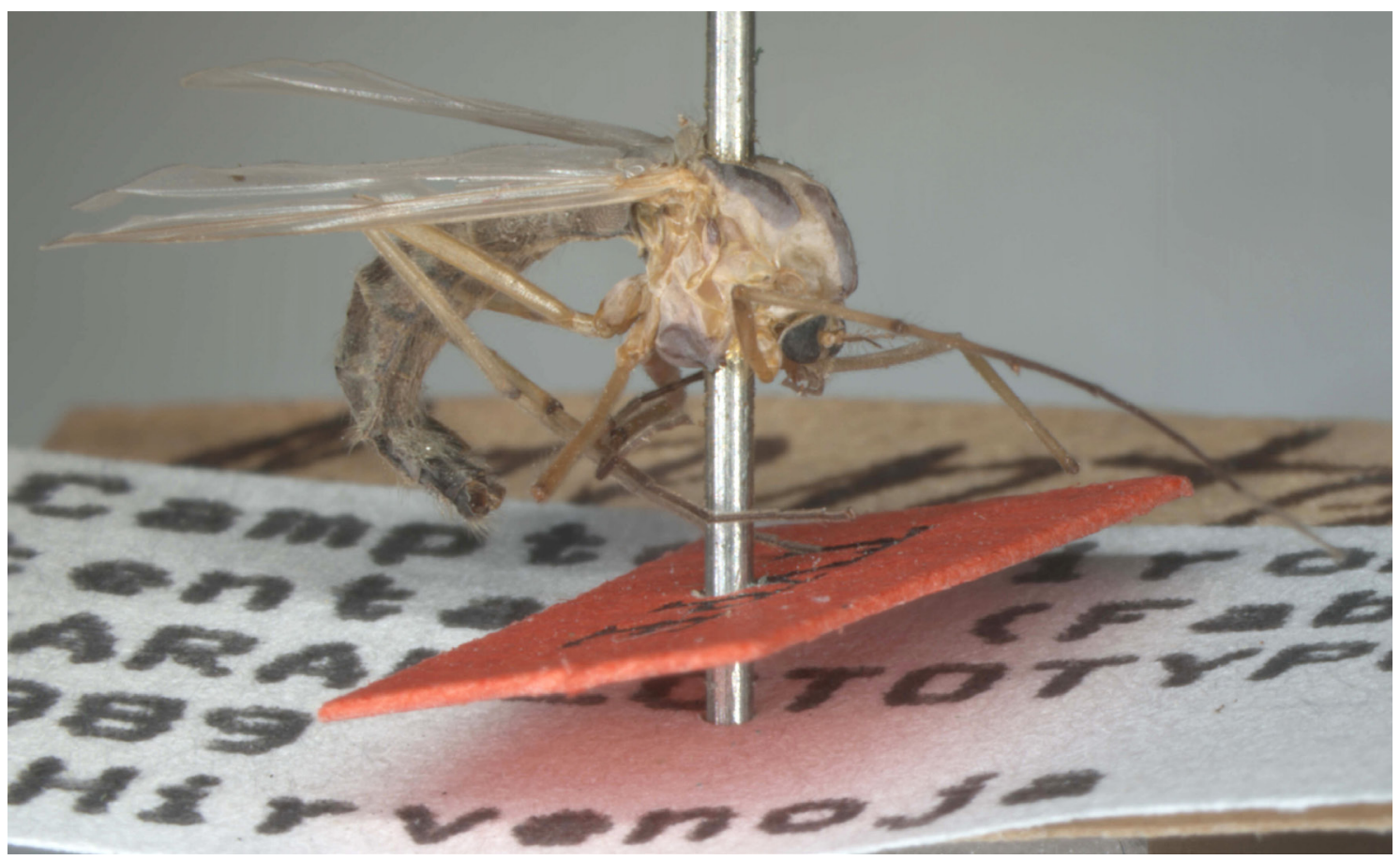

Figure 1. Chironomus tentans Fabricius; paralectotype (ZMUC, Copenhagen), lateral view. The lectotype, also an adult female, has been slide-mounted (Hirvenoja 2006). Photo by M. Kotrba \& M. Spies. 


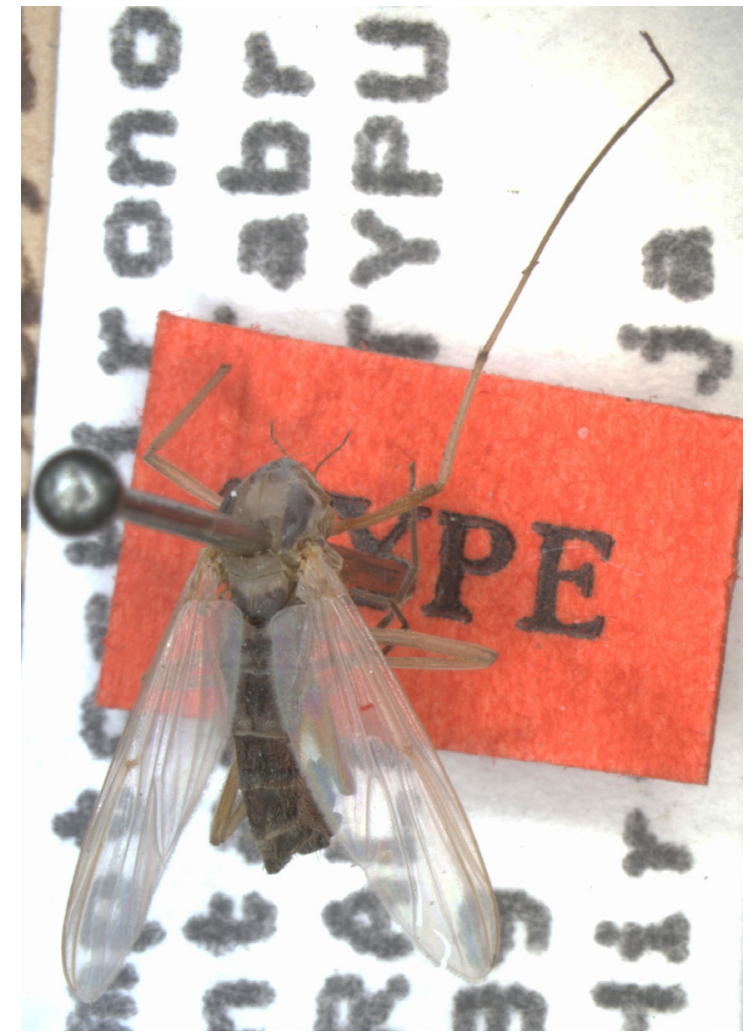

Figure 2. Chironomus tentans Fabricius; paralectotype, dorsal view. Photo by M. Kotrba \& M. Spies.
As in the case of Tipula monilis, positive species identification of the Linnean specimens of T. plumo$s a$ would require microscopic evaluation of at least partial slide mounts. However, the special permission that would have to be obtained for such analysis is not the only obstacle here, as shall be discussed in the following text sections.

\section{Types to guide usage, or vice versa?}

The International Code of Zoological Nomenclature certainly is not the best guideline one could think of, but we cannot do without such a framework, and the Code is the only one around that has long been applied and can be applied reasonably. In its currently effective edition (ICZN 1999) the Code has attempted to serve the interests of scientific communication by allowing the application of taxon names to be influenced more by their recent usage rather than exclusively by criteria tied to the respective original publication. While this more flexible approach can be beneficial in some cases (for one example, see Spies \& Sæther 2004: 27, second paragraph from top), it seems questionable whether the apparent conflict between the Linnean specimens of Tipula plumosa and the usage of Chironomus plumosus constitutes such a case.

After my presentation in Trondheim I heard the expected argument that any change to the application of the name Chironomus plumosus to make the latter reflect the taxonomic identity of the Linnean specimens would cause significant difficulties with accessing corresponding data published earlier not only in taxonomy, but also in ecology, faunistics, etc. While this argument, of course, has its merit in principle, it seems to miss the essential mark here. With the possible exception of identifications based on karyological/cytological evidence (i.e. on the larval giant chromosome banding patterns), 'recent usage' (whichever way one might define this term) of the name C. plumosus can hardly be seen as anywhere near unanimous and stable. Instead, wherever identification as C. plumosus was not based on karyological determinations, and especially wherever the methods or references used to arrive at such identification were not made sufficiently clear, one cannot determine reliably to which of the species in the Chironomus plumosus sibling species aggregate (e.g., Hirvenoja 2006) the corresponding data actually apply. Incidentally, for the same reason we used to be unable to address the issues - much more interesting to the biologist than matters of nomenclature - which species Linnaeus had encountered, whether it still lives where he found it, why not if it does not, and so on.

Consequently, it is quite doubtful that there has been any "prevailing usage" (ICZN 1999) of the name $C$. plumosus, and thus any corresponding body of reliable biological data, that is definable and significant enough so that it could or should be protected in place of original facts such as the taxonomic identity of the type material. On the contrary, it seems that recognizing the Linnean specimens as syntypes would not decrease but even increase stability of nomenclature and quality of the corresponding dataset, by finally providing a basis for reproducible species identifications in all life stages, where previously only larvae could be assigned to a 'cytospecies', the name for which has not been tied to any reproducible voucher.

It can be debated whether the current guidelines governing typification - e.g. the selection, designation, safe storage and consultation of physical vouchers such as type specimens - have been sufficient or require adaptation to progress in taxonomic methods. Conceivably, the assignment of type status could be made more flexible, instead of forcing taxonomists to work with or around specimens that are original types but no longer sufficiently informative. Such modifications could allow subsequent assignment of voucher status to carriers of information not included among the original type material, e.g. to specimens of other life stages reliably associated later, or to samples on the molecular level. However, this topic would be one for a separate discussion (see below) beyond the scope of the present paper. 


\section{Evidence versus hearsay}

Have you ever played or watched the game variously called '(broken) telephone', 'grapevine', 'whisper down the lane', etc.? In this pastime enjoyed in numerous variations the world over, information is transmitted along a chain of people, with each individual transfer involving two persons only, such that other players up or down the line cannot perceive or control the content of any transfer in which they are not directly involved. The attraction of this setup to an audience watching this game, e.g. on television, is as follows. "Errors typically accumulate in the retellings, so the statement announced by the last player differs significantly, and often amusingly, from the one uttered by the first. Some players also deliberately alter what is being said in order to guarantee a changed message by the end of it." (http://en.wikipedia.org/wiki/ Chinese whispers).

Does this, by 'chance', remind you of any tradition that has been going on in chironomid research in general, and especially in the large body of literature using names in Chironomus? If it does not, then here is an example which also illustrates why identification of the 'Camptochironomus' species represented by the Linnean specimens under Tipula plumosa is not as easy as one should expect in a taxon, in which no more than two valid species names are currently recognized in Europe (Spies \& Sæther 2011).

Basically, all taxonomic distinctions of Camptochironomus species to this day derive from the very brief characterizations proposed by Edwards (1929) for two species concepts under the names C. tentans Fabricius, 1805 and C. pallidivittatus Malloch, 1915. Edwards (1929: 382) stated: "I find there is a small but constant difference in the hypopygium, and therefore treat the two as distinct. They superficially resemble C. plumosus." [The latter fact, by the way, could help explain why workers after Linnaeus have misapplied Tipula plumosa for species in Chironomus s. str.] Edwards' diagnoses hardly presented any character state distributed discretely between the two supposed species; instead, one was said to be "rather smaller and lighter", with an "anal point rather differently shaped", and so on. The illustrations provided (op.cit.: 381, fig. $12 \mathrm{a}, \mathrm{b}$ ) do not show any full hypopygium as given for many other species in that work, but limit themselves to details of the anal point and flanking parts of the anal tergite. As could have become obvious a long time ago, the appearance of such parts in a microscope preparation can vary significantly with orientation of the specimen in the mount, degree of maceration, pressure when applying the cover slip, etc. No number of specimens analysed was given by Edwards to support his claim of a difference "constant" across variation to be expected among preparations studied, individuals in a sample, or populations of one or more species.

Apparently, Edwards (1929) had not seen any type of C. tentans Fabricius or C. pallidivittatus Malloch, but merely applied those names from the literature to his British material. In spite of this and the quite obviously less than water-tight identifications (see, e.g., Hein \& Schmulbach 1971: 458), everyone in the subsequent long chain of authors on these and other Camptochironomus species (Townes 1945, Beermann 1955, Hein \& Schmulbach 1971, Sæther 1977, Shobanov et al. 1999, Langton \& Pinder 2007 - to name just a few cornerstone examples) have merely continued the game started (in this case) by Edwards, working mostly from more or less uncritically accepted information handed down along that line of letters on patient paper. To my knowledge I am now the first ever to gather all relevant voucher material (in this case by Fabricius, Malloch, and Edwards) for direct comparison. [Incidentally, I also seem to be the first chironomid worker since Linnaeus to have looked at his specimens of non-biting midges.]

As shown repeatedly (e.g. in Spies \& Sæther 2004) there is one case like this after another that would have to be looked at seriously - which would be necessary if, in contrast to audiences watching 'whisper' games, our purpose in chironomid research runs a little deeper than trivial amusement. Taking such a hard look, then, one cannot help but find that anything we present without truly reproducible evidence is tantamount to hearsay or speculation, i.e. essentially unreliable, and does not qualify to be labeled and employed as science. If significant portions of the data in any system such as chironomid research are non-reproducible, e.g. because they are not based on evidence that remains accessible and observable, then the system is degraded from one built on, and aiming for, evidence-based knowledge to one running on mere beliefs. If members of a research community like ours are inclined or forced to blindly follow what they have seen in publications only, rather than being willing and able to critically test what they examine directly, then entropy inadvertently growing underneath a seemingly orderly surface is bound to cause the corresponding data and system to deteriorate rather than increase in practical value. 


\section{Towards a discussion}

Against the above background, please consider the following questions.

- Has there not been long-standing, significant imprecision and inconsistency in the application of the name Chironomus plumosus?

- Are situations like this not exactly what typification has been invented for, and with good reason?

- Does reinterpretation of the name Tipula plumosa L. in accordance with original type specimens not constitute a good chance to increase or, rather, finally establish nomenclatural stability in this case, in which we have had only superficial semblance of stability, at best?

- If using and quoting taxonomic names with credit to the authors who have made them available is supposed to honor these people, would Linnaeus consider himself honored if we knowingly apply the name Chironomus plumosus to a species different from the one he coined it for?

- How can museums and other institutions - to which many of us would like to be able to look for employment - justify to funding agencies, etc., the efforts necessary to build, maintain or even improve the collections we would need and like to have at our disposal, if we do not actively and scientifically support them in this? Which parts of such collections could be more important to use and support than the holdings of type material?

- Are we allowing too much of chironomid research to run like a game of 'whispering down the lane'? Or are we doing enough to make and keep every important bit we publish scientifically reproducible, so that we and others depending on input from us may work with a well-founded and well-growing body of reliable and useful information that deserves to be called knowledge?

It would be most welcome if answers to these questions, arguments supporting or countering any of those presented here, or any other constructive contributions, could be exchanged in a wide-open discussion. One appropriate forum for this could be the Chironomidae mailing-list (to sign up see https://lists.ansatt.ntnu.no/ vm.ntnu.no/info/chironomidae), even though so far the list has seen as poor participation as several other potentially highly useful services offered to the chironomid 'community'.

In closing, I would like to declare that responses, as well as silence, on the issues raised in this contribution will play no small part in determining whether and how I will proceed concerning the Linnean chironomids and similar matters. Consequently, if you have an opinion and would like to see it count, then by all means do let it be known.

\section{References}

Beermann, W. 1955. Cytologische Analyse eines Camptochironomus-Artbastards. I. Kreuzungsergebnisse und die Evolution des Karyotypus. - Chromosoma 7: 198-259.

Day, M.C. and Fitton, M.G. 1978. Re-curation of the Linnaean Hymenoptera (Insecta), with a reassessment of the taxonomic importance of the collection. - Biological Journal of the Linnean Society, 10: 181-198.

Edwards, F.W. 1929. British non-biting midges (Diptera, Chironomidae). - Transactions of the Royal Entomological Society of London 77: 279-430.

Fittkau, E.J. 1962. Die Tanypodinae (Diptera: Chironomidae). (Die Tribus Anatopyniini, Macropelopiini und Pentaneurini). - Abhandlungen zur Larvalsystematik der Insekten 6: 1-453.

Hein, J. and Schmulbach, J.C. 1971. Intraspecific and interspecific breeding behavior of Chironomus pallidivittatus (Dipt., Chironomidae). - Canadian Entomologist 103: 458-464.

Hirvenoja, M. 2006. Contributions to the taxonomy and ecology of the Chironomus plumosus sibling species aggregate (Diptera: Chironomidae): the brackish water populations in the Tvärminne area, Finland. - Entomologica Fennica 17: 373-380.

ICZN = International Commission on Zoological Nomenclature. 1999. International Code of Zoological Nomenclature. Fourth Edition. - International Trust for Zoological Nomenclature, London. xxix $+306 \mathrm{p}$. 
Langton, P.H. and Pinder, L.C.V. 2007. Keys to the adult male Chironomidae of Britain and Ireland. Volumes 1 and 2. - Freshwater Biological Association, Scientific Publication 64: $239+168$ p.

Linnaeus, C. 1746. Fauna svecica sistens animalia sveciae regni: ... - L. Salvius, Stockholm. [xxviii] + 411 p., 2 pls.

Linnaeus, C. 1758. Systema naturae per regna tria naturae, ... Tomus I. Editio decima, reformata. - L. Salvius, Stockholm. [iv] +824 p.

Linnaeus, C. 1760 (“1761”). Fauna svecica sistens animalia sveciae regni: ... Editio altera, auctior - L. Salvius, Stockholm. [48] +578 p.

Sæther, O.A. 1977. Female genitalia in Chironomidae and other Nematocera: morphology, phylogenies, keys. - Bulletin of the Fisheries Research Board of Canada 197: 1-209.

Sæther, O.A. and Spies M. 2011. Fauna Europaea: Chironomidae - In: Beuk, P. \& T. Pape (eds.) Fauna Europaea: Diptera Nematocera. Fauna Europaea version 2.4. Available at: http://www.faunaeur.org/

Shobanov, N.A., Kiknadze, I.I. and Butler, M.G. 1999. Palearctic and Nearctic Chironomus (Camptochironomus) tentans (Fabricius) are different species (Diptera: Chironomidae). - Entomologica scandinavica 30: 311-322.

Spies, M. and Sæther, O.A. 2004. Notes and recommendations on taxonomy and nomenclature of Chironomidae (Diptera). - Zootaxa 752: 1-90.

Townes, H.K., Jr. 1945. The Nearctic species of Tendipedini (Diptera; Tendipedidae (= Chironomidae)). American Midland Naturalist 34: 1-206. 